\title{
Spatiotemporal Analysis of Drought Characteristics in Song-Liao River Basin in China
}

\author{
Xiaojing Shen, ${ }^{1,2} \mathrm{Xu} \mathrm{Wu}^{3,4}$ Xinmin Xie, ${ }^{1,2}$ Zhenzhen Ma, ${ }^{1,2}$ and Meijian Yang \\ ${ }^{1}$ State Key Laboratory of Simulation and Regulation of Water Cycle in River Basin, China Institute of Water Resources and \\ Hydropower Research (IWHR), Beijing 100038, China \\ ${ }^{2}$ Water Resources Department, China Institute of Water Resources and Hydropower Research (IWHR), Beijing 100038, China \\ ${ }^{3}$ Zhejiang Guangchuan Engineering Consulting Co., Ltd, Hangzhou 310000, China \\ ${ }^{4}$ Zhejiang Institute of Hydraulics \& Estuary, Hangzhou 310000, China \\ ${ }^{5}$ Department of Civil and Environmental Engineering, University of Connecticut, Storrs, CT 06269, USA
}

Correspondence should be addressed to Xu Wu; wxmqhz@163.com

Received 18 March 2017; Revised 10 May 2017; Accepted 24 May 2017; Published 13 July 2017

Academic Editor: Efthymios I. Nikolopoulos

Copyright (C) 2017 Xiaojing Shen et al. This is an open access article distributed under the Creative Commons Attribution License, which permits unrestricted use, distribution, and reproduction in any medium, provided the original work is properly cited.

The monthly accumulated precipitation and monthly average temperature of 117 meteorological stations in Song-Liao River Basin (SLRB) were used to calculate the Standardized Precipitation Evapotranspiration Indices (SPEI) to analyze the drought characteristics, including long-term trends, drought affected area, climate abrupt change, intensive drought occurrence regions, and drought durations during 1964-2013 with the support of GIS. The Area Drought Severity (ADS), a comprehensive index, is proposed to assess both the variations of drought degree and the extent of the drought affected area. The results revealed that (1) the drought happening probability and degree are rising and the affected areas of all degrees of drought have an increasing trend during the last 50 years; (2) there is a climate abrupt change which occurred in around 1994, and the area with declining SPEI is larger than that with declining SPI, which could be due to the rising temperature after the climate abrupt change; (3) all degrees of drought occurrence probability increased, and the intensive drought occurrence regions altered from the northern SLRB to the southwestern SLRB after the climate abrupt change; (4) the drought duration increased from 1994, and the increased drought durations occurred in most parts of SLRB.

\section{Introduction}

Song-Liao River Basin (SLRB) is situated in the northeastern part of China. It is the main grain producing area in China and yielded more than $20 \%$ of the total national food in the past 20 years. However, the increasing dryness would influence the development of agriculture and social economy. Therefore, further study on the annual and seasonal drought characteristics in SLRB has essential significance.

$\mathrm{Ma}$ and $\mathrm{Fu}$ proposed that the frequency of drought was significantly increasing in Northeast China [1]. And Zou et al. calculated the Palmer Drought Severity Index (PDSI) with monthly air temperature and rainfall data from 1951 to 2003 and discovered an increasingly serious drought crisis in North China, especially since the late 1990s [2]. In addition, Yao et al. indicated that the spring drought index of northeastern China showed a declining trend [3]. Moreover, the study of $\mathrm{He}$ et al. demonstrated that the drought area in northeast plain and southern Heilongjiang province was gradually expanding and the drought frequency was rising [4]. Furthermore, severe and extreme droughts have become more serious since the late 1990s for all of China, with dry area increasing by $3.72 \%$ per decade, especially in North China, Northeast China, and western Northwest China, and the increasing frequency of long lasting drought events in Northeast China was discovered by Yu et al. [5]. Meanwhile, $\mathrm{Xu}$ et al. analyzed the drought characteristic in China during the 1960-2012 with a 3-dimensional clustering method. The result showed that, in the past half century, the most severe drought occurred during the 19621963 and the 2010-2011 with widely drought affected area [6]. 
In previous studies, different drought indices were used to evaluate the drought characteristic. The Palmer Drought Severity Index (PDSI), the Standard Precipitation Index (SPI), the Standard Precipitation Evapotranspiration Index (SPEI), and so forth were widely used to monitor the dryness [7]. The Palmer Drought Severity Index (PDSI) considers prior precipitation, moisture supply, runoff, and evaporation demand (ET). However, the PDSI also has deficiencies of limitation in spatial comparability, subjectivity in relating drought conditions, and so forth, which will influence the index value $[5,8]$. In addition, the Standard Precipitation Index (SPI) is also one of the most widely used drought indices with simple calculation and flexible time scale, while it is based on rainfall only [9]. However, in some researches, the drought indices were corrected or modified to better adapt to the local climate and the underlying surface condition. Vicente-Serrano et al. proposed the Standard Precipitation Evapotranspiration Index (SPEI), which considers the evapotranspiration, and also has the simplicity of calculation and the multitemporal nature of the SPI [10]. In this study, the Standardized Precipitation Evapotranspiration Indices (SPEI) and the Area Drought Severity (ADS), a comprehensive index calculated by the averaged SPEI and the drought percentage area, were used to further research the spatiotemporal variations of drought over 50 years from 1964 to 2013 in SLRB. The Standardized Precipitation Indices (SPI) were utilized to analyze the impact of the warming climate on drought by comparing the spatial drought trends based on SPI and SPEI with the support of GIS.

\section{Study Area}

Song-Liao River Basin is located between $114^{\circ} \mathrm{E}-135^{\circ} \mathrm{E}$ and $37^{\circ} \mathrm{N}-53^{\circ} \mathrm{N}$ with the highest latitude in China. The total area of SLRB is $124.92 \mathrm{~km}^{2}$, in which mountain area occupies $85.03 \mathrm{~km}^{2}, 68$ percent of the total area, and the rest $39.89 \mathrm{~km}^{2}$ is the flat area, accounting for 32 percent of the total area (Figure 1). The area includes Songhua River Basin (SRB) and Liao River Basin (LRB) and crosses five provinces including most parts of Liaoning province, the entire Jilin province, Heilongjiang province, eastern part of Inner Mongolia, and a small part of Hebei province.

SLRB has the humid and semihumid continental monsoon climate characterized by hot and rainy summer and cold and dry winter. The annual accumulated precipitation and annual temperature of SLRB averaged during 1964-2013 are $521.8 \mathrm{~mm}$ and $5.0^{\circ} \mathrm{C}$ separately. The declining precipitation and rising temperature contribute to the increasingly serious climate drought, especially the seasonal drought which would seriously impact the agriculture yield.

\section{Date and Method}

3.1. Date Processing. The daily precipitation and air temperature data during 1964-2013 in 117 meteorological stations within SLRB were selected to calculate the SPEI and SPI indices. This comparative complete dataset is obtained from China Meteorological Data Sharing Service System. The missing values in each station were filled with the mean values

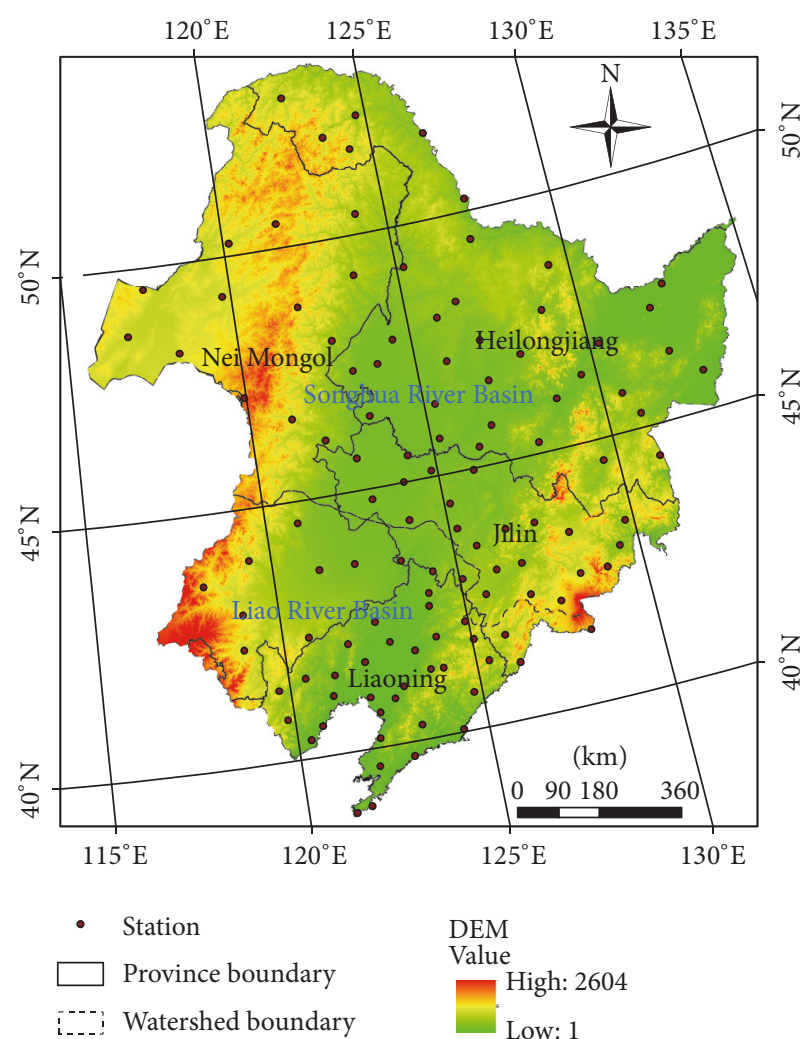

FIgURE 1: The geological location of SLRB and Digital Elevation Model (DEM).

of the nearest 5 stations calculated by the Tyson Polygon Method.

Annual drought characteristics were analyzed based on SPEI-12. In addition, SPEI-3 was calculated for seasonal drought analysis. Tyson Polygon Method is one of the widely used methods to get the average of precipitation and SPEI. It considers the area weight and the calculation precision is more reliable if it has enough meteorological stations in the study area [11]. Therefore, Tyson Polygon Method was applied to get the overall SPEI values of Song-Liao River Basin. Moreover, the Area Drought Severity (ADS) was proposed to comprehensively assess the variations of drought degree and the extent of the drought affected area. The nonparametric Mann-Kendall rank correlation test was selected to detect the drought trend and abrupt change of the sample sequence $[12,13]$. Moreover, the spatial distributions of the MK trend statistic of SPEI-12 and SPI-12 were compared to manifest the influence of temperature on drought. The drought magnitude was defined as five types and each standard of SPEI and SPI range was shown in Table 1. Furthermore, the drought area and the spatial distribution of drought were analyzed by the Inverse Distance Weighting Interpolation Method.

3.2. Calculation of SPI. The SPI was developed by McKee et al. [9]. It is widely used to identify drought periods and severity with multiple timescales. Original rainfall series of each station was used to calculate the SPI. The series 
TABLE 1: Classification standard of drought based on SPEI.

\begin{tabular}{lc}
\hline Drought classification & SPEI \\
\hline Normal & More than -0.49 \\
Light drought & -0.99 to -0.5 \\
Moderate drought & -1.49 to -1.0 \\
Severe drought & -1.99 to -1.5 \\
Extreme drought & Less than -2.0 \\
\hline
\end{tabular}

$(x)$ was fitted to a gamma probability distribution function [14]:

$$
g(x)=\frac{1}{\beta^{\alpha} \Gamma(\alpha)} x^{\alpha-1} e^{-x / \beta}, \quad \text { for } x>0,
$$

where $\alpha$ and $\beta$ are shape and scale factors, respectively.

The maximum likelihood solutions were used to optimally estimate the parameters, $\alpha$ and $\beta$, for each station:

$$
\begin{aligned}
& \alpha=\frac{1}{4 A}\left(1+\sqrt{1+\frac{4 A}{3}}\right), \\
& A=\ln (\bar{x})-\frac{\sum \ln x}{n},
\end{aligned}
$$

where $n$ is the sample size of the rainfall series.

$$
\beta=\frac{\bar{x}}{\alpha}
$$

The mathematical cumulative probability function was given by

$$
G(x)=\int_{0}^{x} g(x) d x=\frac{1}{\beta^{\alpha} \Gamma(\alpha)} \int_{0}^{x} x^{\alpha-1} e^{-x / \beta} d x .
$$

Because the gamma function was undefined for $x=0$ and the precipitation may contain zero, the cumulative probability becomes

$$
H(x)=q+(1-q) G(x),
$$

where $q$ is the probability of zero.

Then, the cumulative probability $H(x)$ was transformed to the standard normal distribution to obtain the SPI.

3.3. Calculation of SPEI. The computation of the SPEI is as follows $[5,15]$.

The Thornthwaite method was used to calculate the potential evapotranspiration (PET) [16]:

$$
\operatorname{PET}=16 a\left(\frac{10 T_{i}}{I}\right)^{k},
$$

where $T_{i}$ is the monthly mean temperature $\left({ }^{\circ} \mathrm{C}\right) ; I$ is a heat index calculated using

$$
\begin{aligned}
I= & \sum_{i=1}^{12}\left(\frac{T_{i}}{5}\right)^{1.514}, \\
k= & 6.75 \times 10^{-7} I^{3}-7.71 \times 10^{-5} I^{2}+1.79 \times 10^{-2} I \\
& +0.492,
\end{aligned}
$$

where $a$ is a sunshine hour and month related coefficient:

$$
a=\left(\frac{N}{12}\right) \times\left(\frac{M}{30}\right)
$$

where $N$ is the monthly sunshine hour and $M$ is the number of days in each month.

The climate water balance for the month $i$ was calculated as follows:

$$
D_{i}=P_{i}-\mathrm{PET}_{i},
$$

where $D_{i}$ is the deficit or surplus accumulation of the water balance for month $i ; P_{i}$ is the monthly precipitation; $\mathrm{PET}_{i}$ is the monthly potential evaporation.

The accumulated water surplus or deficit series in different time scales were constructed as follows:

$$
D_{n}^{k}=\sum_{i=0}^{k-1}\left(P_{n-i}-\operatorname{PET}_{n-i}\right), \quad n \geq k,
$$

where $k$ is the time scale (month); $n$ is calculation frequency.

The log-logistic distribution, which correlates best to the $D$ series compared with Pearson Ш, lognormal, and general extreme values by Vicente-Serrano, was selected for normalizing the $D$ series to obtain SPEI [15]. The probability density function was used as follows:

$$
f(x)=\frac{\beta}{\alpha}\left(\frac{x-\gamma}{\alpha}\right)^{\beta-1}\left[1+\left(\frac{x-\gamma}{\alpha}\right)^{\beta}\right]^{-2},
$$

where $\alpha, \beta$, and $\gamma$ are scale, shape, and origin parameters, separately.

The probability distribution function of the log-logistic distribution for $D$ series was given as follows:

$$
F(x)=\left[1+\left(\frac{\alpha}{x-\gamma}\right)^{\beta}\right]^{-1} .
$$

The SPEI can easily be obtained as the standardized values of $F(x)$ with the following formula:

$$
\begin{aligned}
\text { SPEI } & =W-\frac{C_{0}+C_{1} W+C_{2} W^{2}}{1+d_{1} W+d_{2} W^{2}+d_{3} W^{3}}, \\
W & =\sqrt{-2 \ln (P)} \quad \text { for } P \leq 0.5,
\end{aligned}
$$

where $P$ is the probability of exceeding a determined $D$ value and $P=1-F(x)$; when $P>0.5, P=1-P$. And the constants are

$$
\begin{aligned}
& C_{0}=2.515517, \\
& C_{1}=0.802853, \\
& C_{2}=0.010328, \\
& d_{1}=1.432788, \\
& d_{2}=0.189269, \\
& d_{3}=0.001308 .
\end{aligned}
$$


3.4. Assessment of Area Drought Severity. In order to spatiotemporally assess the variations of drought severity, the Area Drought Severity (ADS), a comprehensive index, was proposed. The ADS was calculated by the averaged SPEI and the percentage of area with SPEI $<0\left(\mathrm{PA}_{-}\right)$or the percentage of area with SPEI $>0\left(\mathrm{PA}_{+}\right)$. This index can assess both the variations of drought (wet) degree and the extent of the drought (wet) affected area. The ADS is defined as follows:

$$
\mathrm{ADS}= \begin{cases}\mathrm{SPEI}_{i} \times \mathrm{PA}_{+}, & \mathrm{SPEI}_{i}>0 \\ \mathrm{SPEI}_{i} \times \mathrm{PA}_{-}, & \mathrm{SPEI}_{i}<0\end{cases}
$$

where SPEI is the weighted average of the study area calculated by the Tyson Polygon Method and $i$ is the timescale (3 months for seasonal drought analysis and 12 months for annual). $\mathrm{PA}_{+}\left(\mathrm{PA}_{-}\right)$is calculated by the Inverse Distance Weighting Interpolation Method. Hence, drought severity is inversely proportional to the value of ADS. This index may avoid overestimation of drought (wet) degree in the case of small (big) SPEI affected small area.

3.5. Mann-Kendall Test. The M-K method was applied in this study to detect the drought abrupt change $[15,17,18]$. For a time series $x$ with a sample size of $n$, assuming that the original time series is random and independent, a rank sequence was constructed as follows:

$$
\begin{aligned}
& s_{k}=\sum_{i=1}^{k} r_{i}, \quad(2 \leq k \leq n), \\
& r_{i}=\left\{\begin{array}{ll}
1 & x_{i}>x_{j} \\
0 & \text { else }
\end{array} \quad j=1,2, \ldots, i .\right.
\end{aligned}
$$

The mean $E\left(s_{k}\right)$ and variance $\operatorname{Var}\left(s_{k}\right)$ of $s_{k}$ are as follows:

$$
\begin{aligned}
E\left(s_{k}\right) & =\frac{k(k-1)}{4}, \\
\operatorname{Var}\left(s_{k}\right) & =\frac{k(k-1)(2 k+5)}{72},
\end{aligned}
$$

$$
(2 \leq k \leq n)
$$

Under the above assumption, statistics $\mathrm{UF}_{k}$ were defined as follows:

$$
\mathrm{UF}_{k}=\frac{s_{k}-E\left(s_{k}\right)}{\sqrt{\operatorname{Var}\left(s_{k}\right)}}, \quad k=1,2, \ldots, n .
$$

The UF curve was made up by all the $\mathrm{UF}_{k}$ points. The antitone sequence UB curve was drawn in the same way. Given the significant levels of $\alpha=0.05$ and $\alpha=0.1$ and the critical values $U_{0.05}= \pm 1.96$ and $U_{0.1}= \pm 1.64$. If $|\mathrm{UF}|>0$, the sequence shows an increasing or decreasing trend. If $\left|U_{k}\right|>$ $U_{\alpha}$, the sequence shows a significant rising or dropping trend. If the intersection of UF curve and UB curve located between the two critical lines, the $x$-axis value of this cut point is the commencement of abrupt change.
3.6. Definition of Drought Duration. Drought duration here is defined as the average number of drought (include all types of drought with SPEI $\leq-0.5$ ) lasting month in a period, which is calculated as follows:

$$
D=\frac{\sum M}{n}
$$

where $M$ is the number of drought month and $n$ is the drought happening times in a period.

\section{Results and Discussion}

4.1. Variations of Drought Severity. The Tyson Polygon Method was applied to get the overall SPEI values of the study area. Figure 2(a) shows the interannual variability of SPEI. Before 1994, most of the SPEI values are positive; SPEI of few years are less than 0 , and only the values of the years from 1966 to 1968 are less than -0.5 ; however, most of the SPEI values are negative except a few years with the values above 0 right after 1994; the SPEI values of the years from 1994 to 1996 are less than -1 . The accumulated SPEI curve depicts that the accumulated SPEI increases from 1968, peaks at about 5 in 1994, then drops sharply after 1994, and gets to a minimum at about -1.4 in 2011. Variability of ADS is shown in Figure 2(b). The accumulated ADS departure shows a similar trend with accumulated SPEI. However, the accumulated ADS departure peaks at about 3.3 in 1994, then drops sharply after 1994, and gets to a minimum at about -2.6 in 2011. Moreover, the accumulated SPEI become negative since 2005, and the accumulated ADS become negative since 1995; the negative accumulated values of ADS occurred earlier than that of SPEI, which demonstrates that bigger drought percentage area and smaller wet percentage area occurred after 1994. Therefore, the SPEI may overestimate the wet degree with big SPEI affected small area, and the drought affected area has been expanding after 1994.

Because of the negative correlations between drought degree and drought indices, the result above indicates that the annual drought in SLRB is becoming serious and frequent especially after 1994.

Figures 3(a)-3(d) demonstrate the interannual variability of SPEI and ADS values in four seasons. From Figure 3 (left), an increasing trend of accumulated SPEI is found in four seasons in the 1970s through the late 1980s, yet it turns out to be an opposite trend since the early 1990s. The accumulated departure curves of seasonal SPEI peak at about 5.9, 5.7, 1.6, and -1.1 in spring, summer, autumn, and winter, respectively, in 1993; however, they drop sharply since 1994. Most of the accumulated SPEI values in autumn are negative with values in few years above 0 , and all of the accumulated values in winter are negative during the past 50 years. It indicates that the seasonal drought is increasingly serious especially in spring and summer, with the accumulated SPEI values decreasing by $59 \%$ and $57 \%$ in spring and summer, separately, since 1994. From Figure 3 (right), it can be found that the negative accumulated values of ADS occurred earlier than that of SPEI in spring, summer, and autumn, separately, which demonstrates that bigger drought percentage area and 


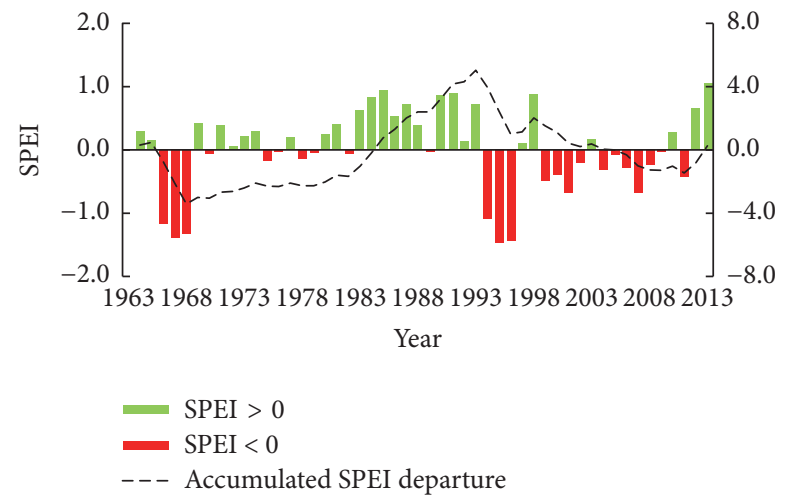

(a)

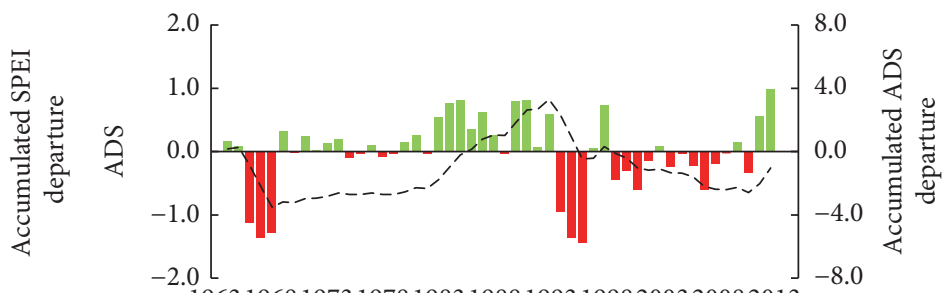

19631968197319781983198819931998200320082013

Year

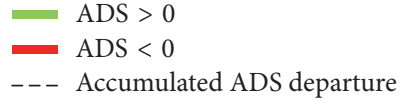

(b)

FIGURE 2: The interannual variability of (a) annual SPEI value and (b) annual ADS value.

smaller wet percentage area occurred after 1994 in these seasons. All these differences may be due to the overestimation of wet degree with big SPEI affected small area, and the drought affected area has been expanding after 1994, especially in spring, summer, and autumn.

4.2. Variations of Drought Area. The 5-year moving average of the drought percentage area in Figure 4 shows that the drought area has an overall increasing trend during the last 50 years; it shows a fluctuant declining trend before 1988, while it increases from the late 1980s with a sharp rising since 1994 and peaks in the mid-2000s at about 74\%; then it has a fluctuant declining trend and ends up in 53\%. Meanwhile, drought percentage areas in four degrees are illustrated in Figures 5(a) and 5(b). It shows that the light drought and the moderate drought are the main drought types of all drought degrees that SLRB face; the affected area of all types of drought manifests an overall increasing trend, especially light drought and moderate drought. From the 5-year moving averages of four types of drought, it can be found that the light drought area ratio has a fluctuant increase from the late $1980 \mathrm{~s}$ and peaks in the late 2000s at about 57\%; the 5-year moving average ratio of moderate drought area increases from 1994 and arrives at the culmination of $15 \%$ in 1998; moreover, the severe and extreme drought percentage areas also have overall increasing trends; the 5-year moving average percentages of the influencing area ratios of sever and extreme drought are lower than $2 \%$ from the mid-70s to 1994; however, the ratios of severe and extreme drought area rise significantly from 1994 and peak at approximately $19 \%$ and $12 \%$ separately in 1998.

Figures 6(a)-6(d) illustrate the variability of drought area in four seasons. From the pictures, it can be noted that the light drought and the moderate drought are the main drought types in four seasons. The drought percentage area has an overall increasing trends in spring, summer, and autumn, especially after 1994, while it has an overall decreasing trend in winter, which is one of the main factors that contribute to the difference between SPEI value and ADS value in this season.

The result indicates that all types of drought influencing regions in SLRB have been expanding from 1964 to 2013 especially after 1994; and the drought affected areas have been expanding in four seasons except winter.

4.3. M-K Test. As given in Figures 2-6, the drought trend in SLRB changes significantly since 1994 . To further explore this phenomenon, $\mathrm{M}-\mathrm{K}$ method was applied to detect the abrupt change of the annual SPEI and annual mean temperature series. Figure 7 (a) indicates that the drought abrupt change happens in around 1994, and Figure 7(b) shows the temperature abrupt change also happens in around 1994; since 1994, the temperature in SLRB has an upward trend even with a significant rising trend since 1998 (significant at $10 \%$ confidence level). The result is highly correspondent with the temporal variability shown in Figures 2-6 that the drought happening probability and drought percentage area rise notably since 1994 .

4.4. The Influence of Warming Climate on Drought. To further research the spatial variations of drought trend under the influence of the warming climate before and after the abrupt change, the spatial distributions of the MK trend statistics of annual SPEI and annual SPI (based on rainfall only) during the 1980s, 1990s, and 2000s were compared based on GIS, and the result is shown in Figures 8(a) and 8(b). It can be observed that the annual SPEI and annual SPI presented remarkable spatial variations in patterns. In the 1980s, SPEI and SPI values of most areas in SLRB present upward (wetness) trend, with only little part in Liaoning province and eastern Heilongjiang province showing downward (dryness) trend. Until the late 1990s, the SPEI values of most parts in Liaoning province and western Jilin province and small part in Inner Mongolia and Heilongjiang province have down trends; however, the SPI values of only half part in Liaoning province, small part of western Jilin province, and little part in Inner Mongolia and Heilongjiang province have down trends. Nevertheless, until the late 2000s, the downward trend of the SPEI values dominates most parts of SLRB, including almost the entire LRB and most parts of SRB, including eastern Inner Mongolia, almost the entire Liaoning province, western and small part of eastern Jilin province, and southern and eastern Heilongjiang province; even significant 


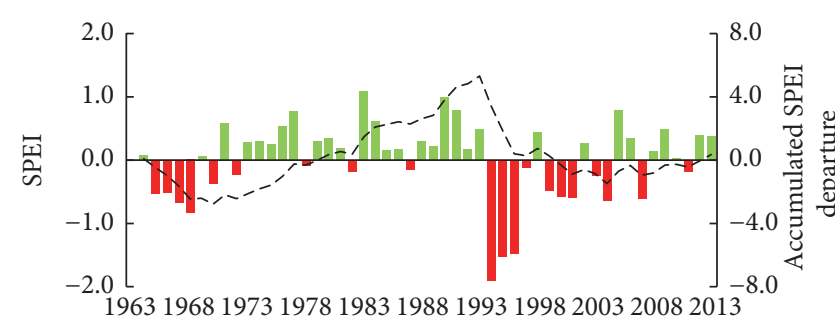

Year
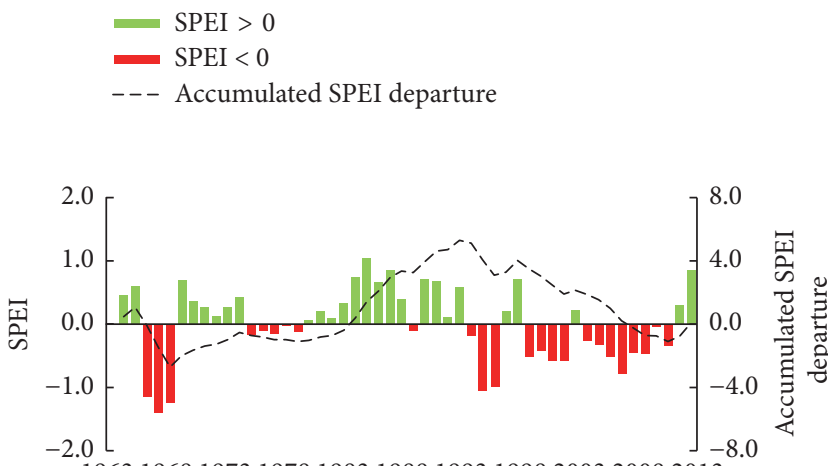

19631968197319781983198819931998200320082013

Year

SPEI $>0$

SPEI $<0$

- - - Accumulated SPEI departure

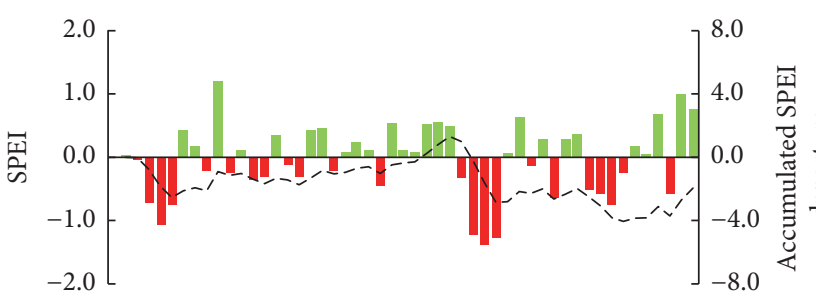

19631968197319781983198819931998200320082013

Year

SPEI $>0$

SPEI $<0$

--- Accumulated SPEI departure

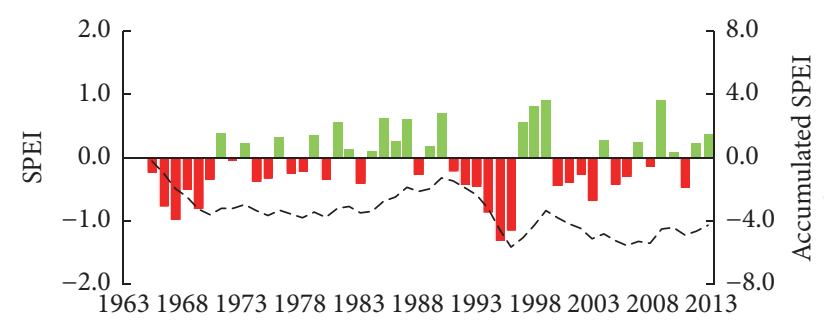

Year

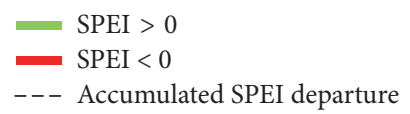

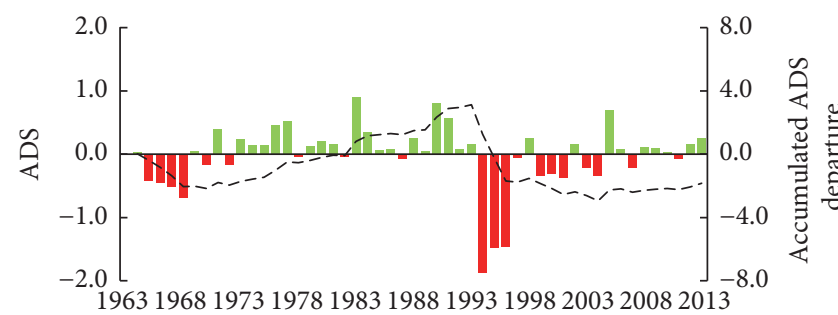

Year

ADS $>0$

ADS $<0$

- - - Accumulated ADS departure

(a)

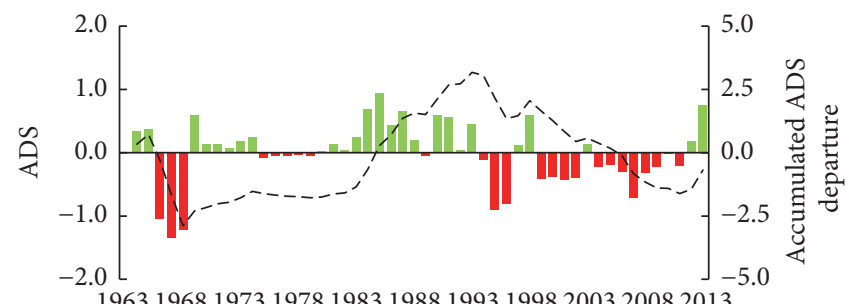

19631968197319781983198819931998200320082013

Year

(b)

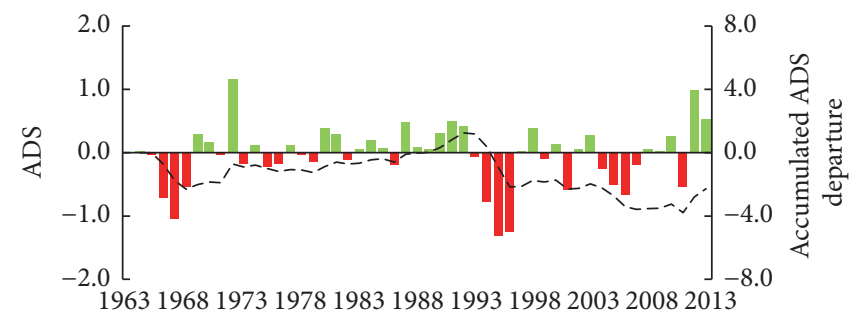

Year

ADS $>0$

ADS $<0$

- - - Accumulated ADS departure

(c)

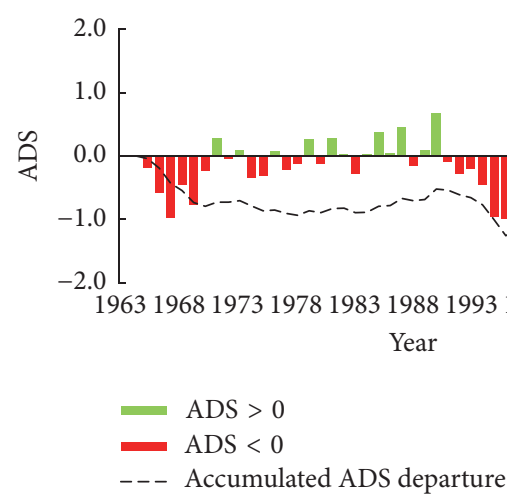

(d)

FIGURE 3: The interannual variability of (a) spring, (b) summer, (c) autumn, and (d) winter SPEI value (left) and ADS value (right). 


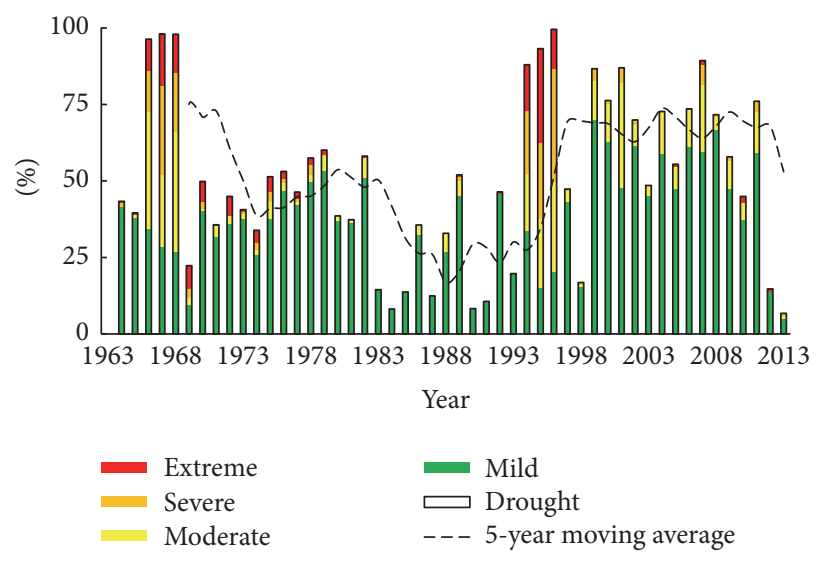

FIGURE 4: The interannual variability of drought area.

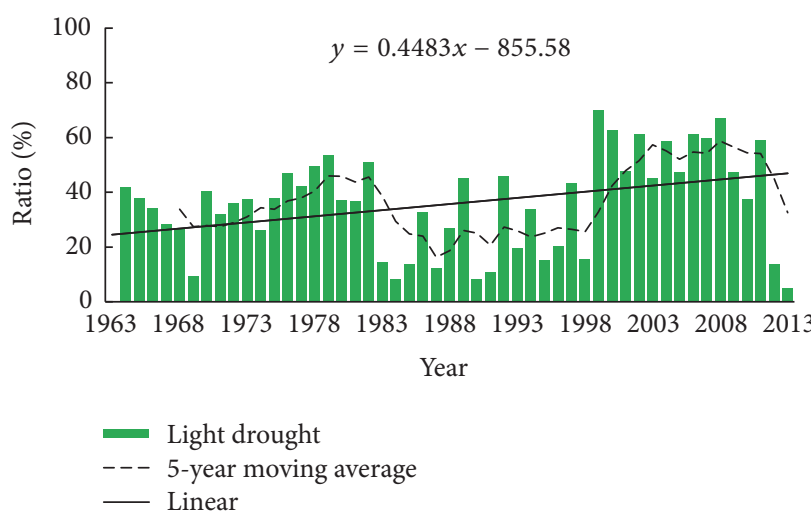

(a) Light drought

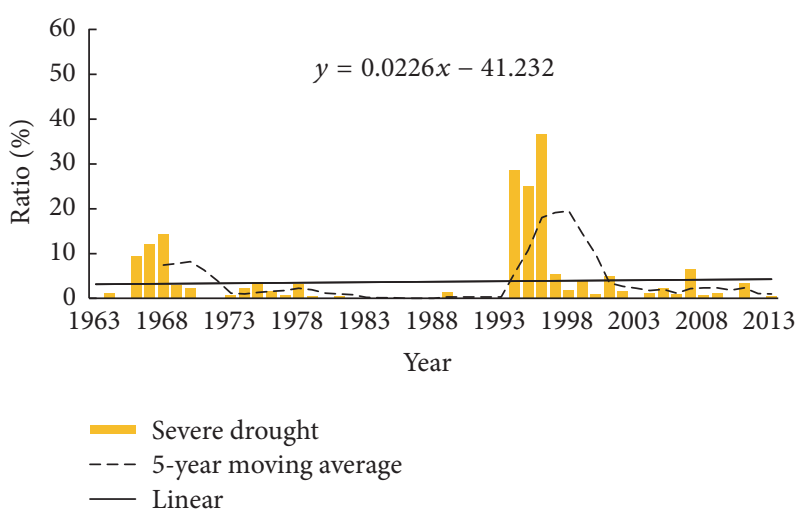

(c) Severe drought

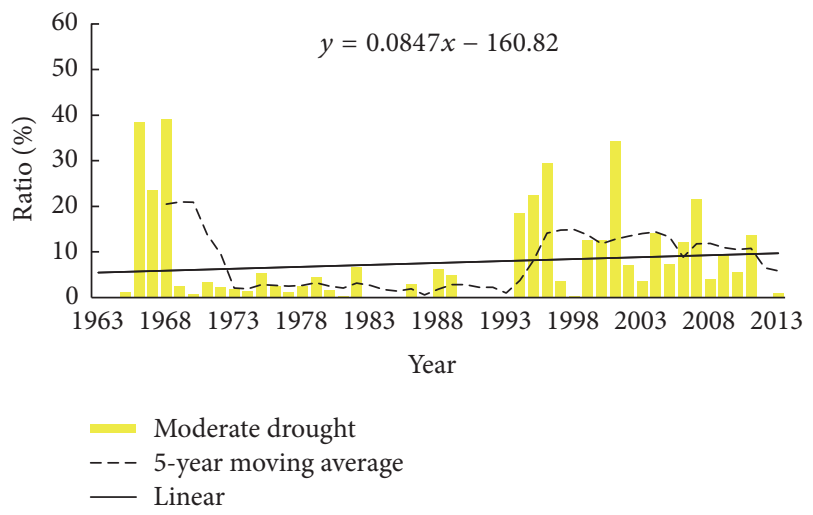

(b) Moderate drought

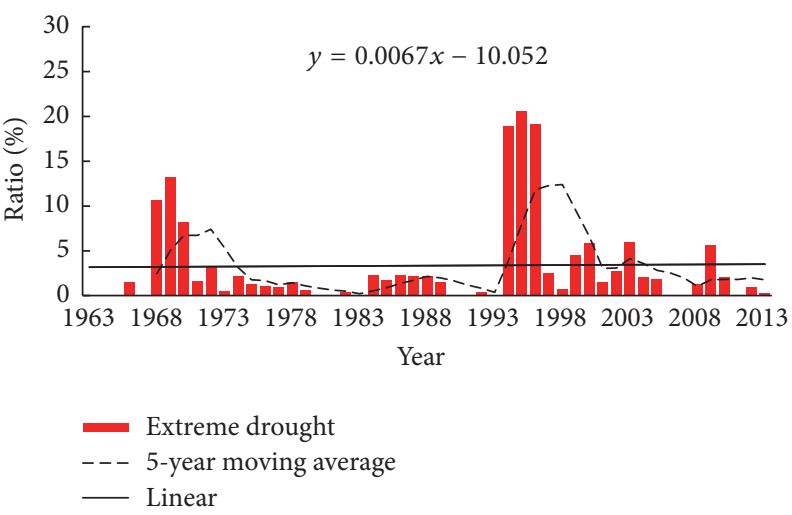

(d) Extreme drought

Figure 5: The interannual variability of drought area in four sublevels.

downward trends (significant at 5\% confidence level) of SPEI were found in parts of western and southern SRB and small part of western LRB; while the downward trend of the SPI values is only found in most parts of LRB and small part of SRB, significant downward trends of SPI were only found in little part of SRB. All in all, it can be seen that the area with declining SPEI is larger than the area with declining SPI, and this could be due to the rising temperature since the mid-90s.
4.5. Variations of Drought Occurrence Probability. The probabilities of different drought events in two time ranges, 1964-1994 and 1995-2013, divided by the abrupt change point were discussed. Table 2 displays the comparison of drought happening rates in two time ranges. The drought (with SPEI $<-0.5$ ) occurrence probability is 40\% during 1964-1994, while it increases to $58.1 \%$ after the climate abrupt change. Happening rates of light drought increased by $12.7 \%$, and the possibility of moderate drought increased by $3.2 \%$ after 

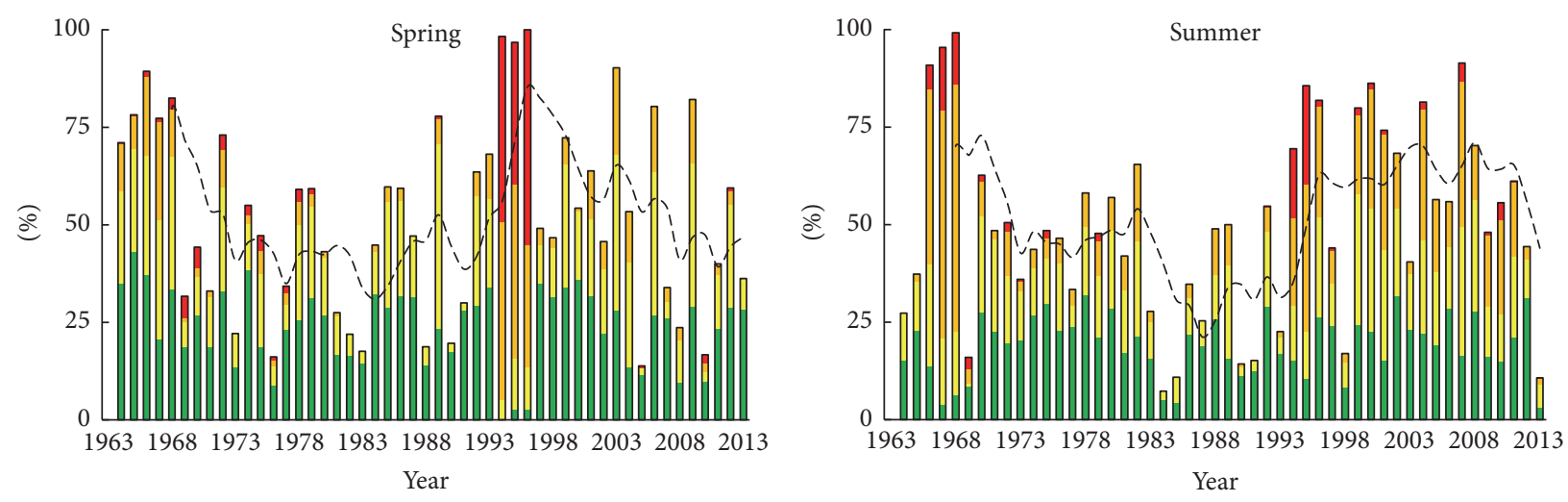

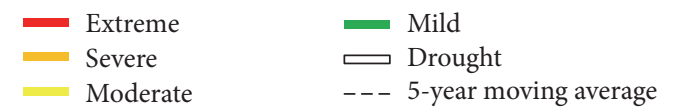

(a)

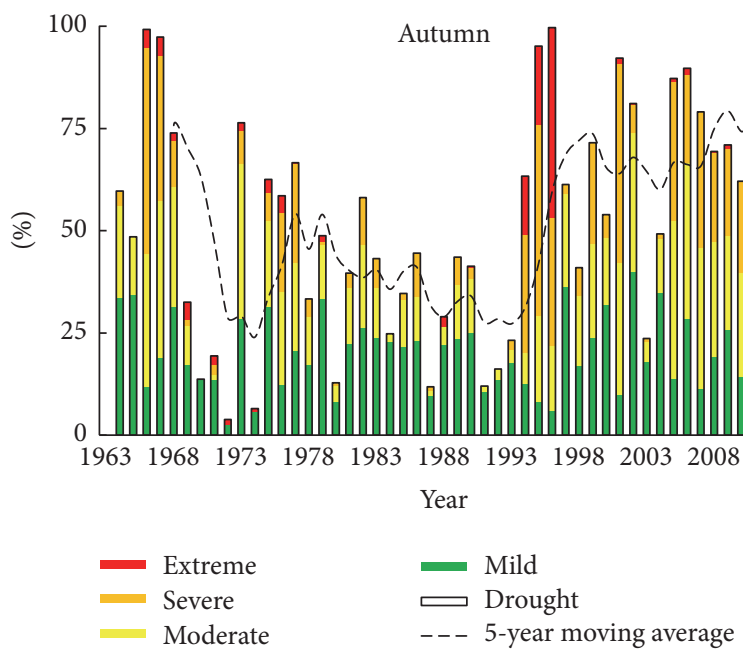

(c)

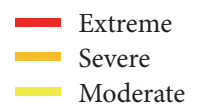

Mild

$\rightleftarrows$ Drought

- - 5-year moving average

(b)

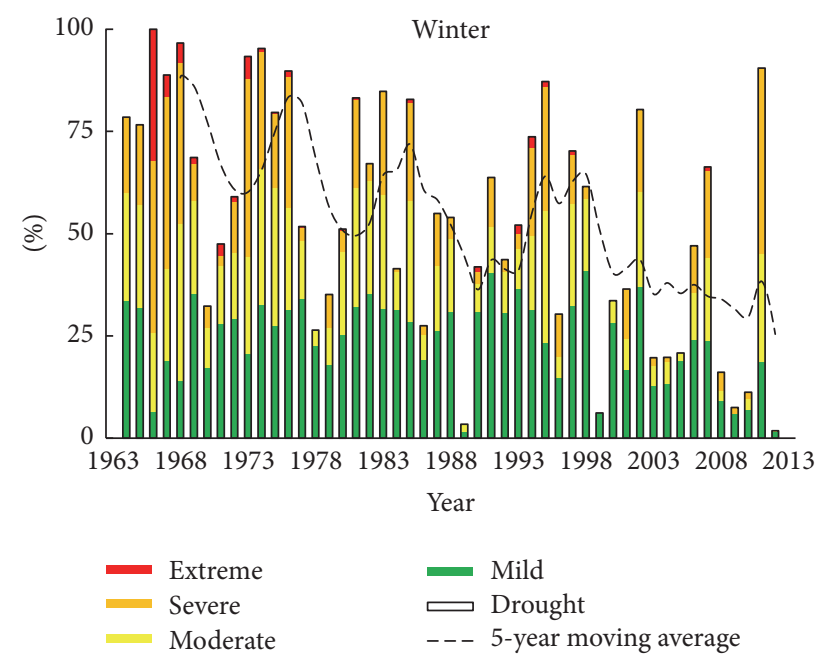

(d)

FIGURE 6: The interannual variability of drought area in four seasons.
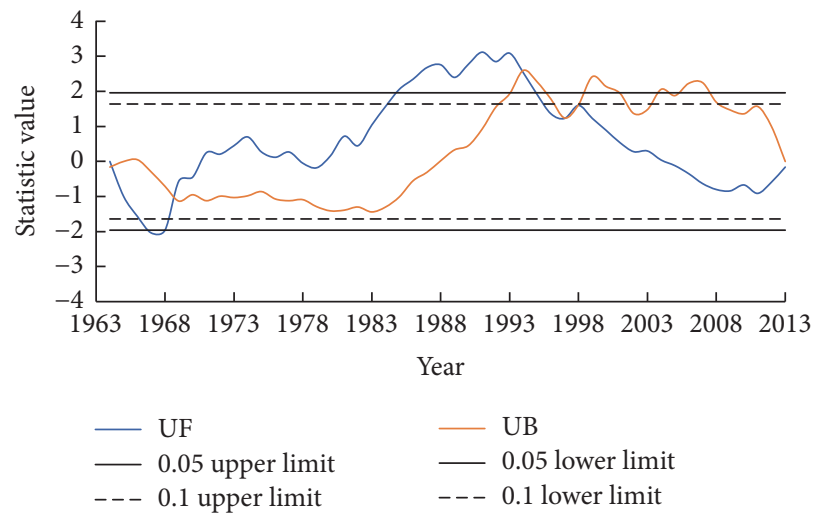

(a)

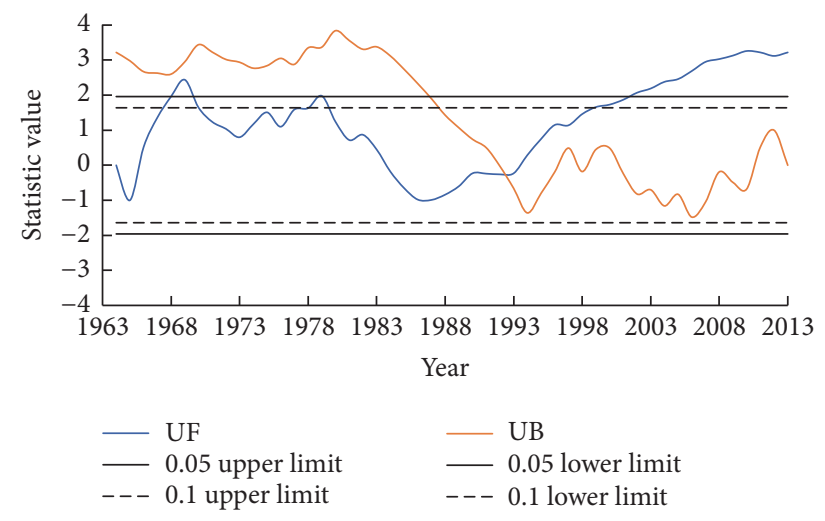

(b)

FIGURE 7: The results of M-K test of (a) SPEI-12 and (b) annual mean temperature. 

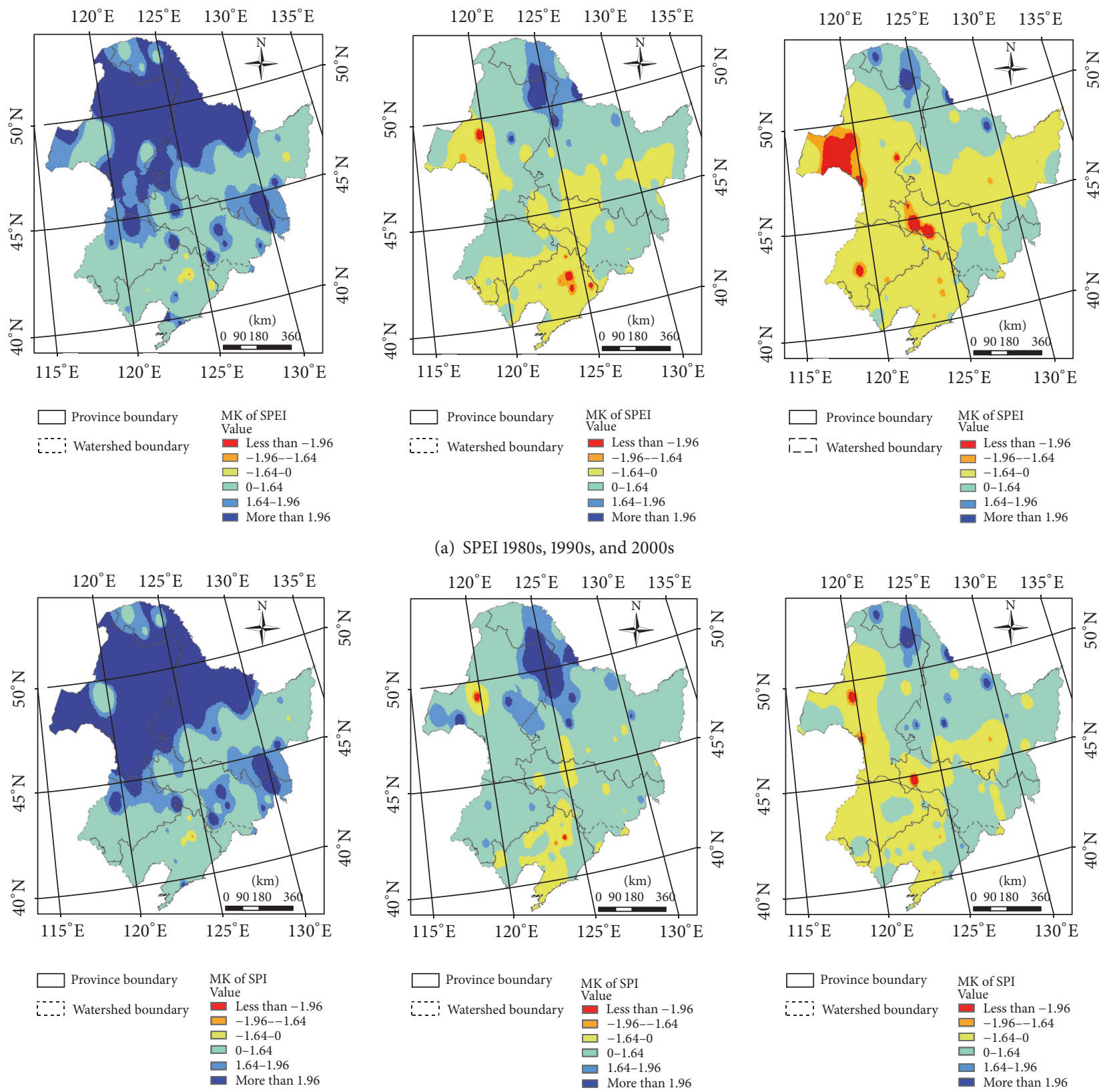

(a) SPEI 1980s, 1990s, and 2000s
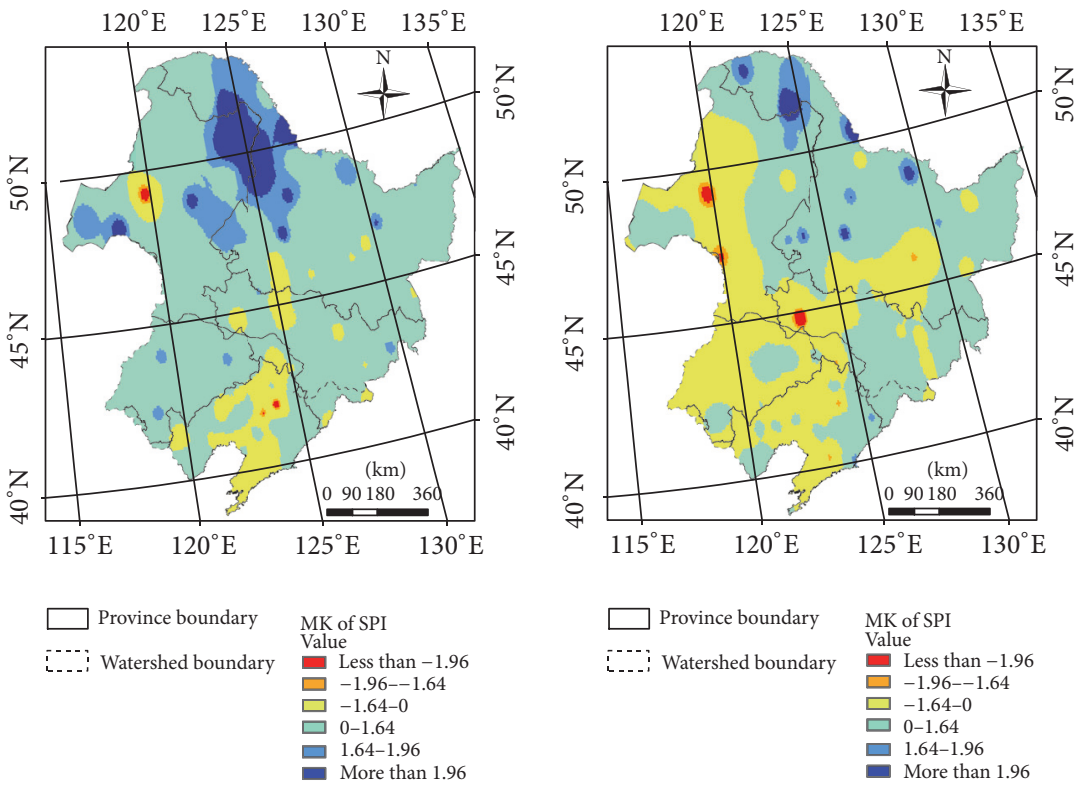

(b) SPI 1980s, 1990s, and 2000s

FIGURE 8: Trend variations of (a) annual SPEI and (b) annual SPI over SLRB from the 1980s through the 2000s.

TABLE 2: The comparison of drought happening rates between 1964-1994 and 1995-2013.

\begin{tabular}{lcc}
\hline Drought degrees & 1964-1994 (\%) & 1995-2013 (\%) \\
\hline Drought & 40 & 58.1 \\
Light & 25.6 & 38.3 \\
Moderate & 12.7 & 15.9 \\
Severe & 1.5 & 3.6 \\
Extreme & 0.2 & 0.3 \\
\hline
\end{tabular}

the abrupt change; the probabilities of severe drought and extreme drought also slightly increased after 1994.
4.6. Movement of Intensive Drought Occurrence Center. To further analyze the variations of spatial distribution of drought in different degrees, Inversed Distance Weight method was used to interpolate the happening probability of different drought events classified by SPEI of 117 stations within SLRB based on GIS in two time ranges. Figures 9(a)-9(e) show the comparison of all kinds of drought happening probability between the two time ranges. Figure 9 (left) demonstrates that, before 1994, drought happened most frequently in northern SRB, southeastern SRB, and eastern LRB with a highest possibility of $63.78 \%$; light drought occurred most likely in northern SRB covered northern Heilongjiang and northeastern Inner Mongolia with a highest 

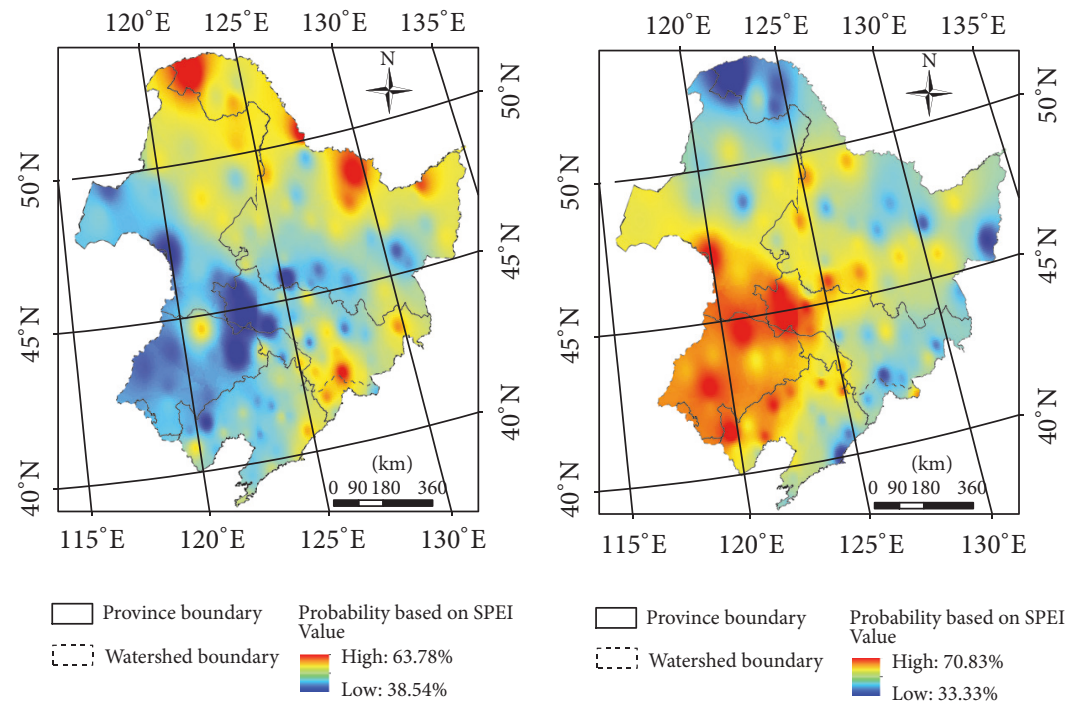

(a)
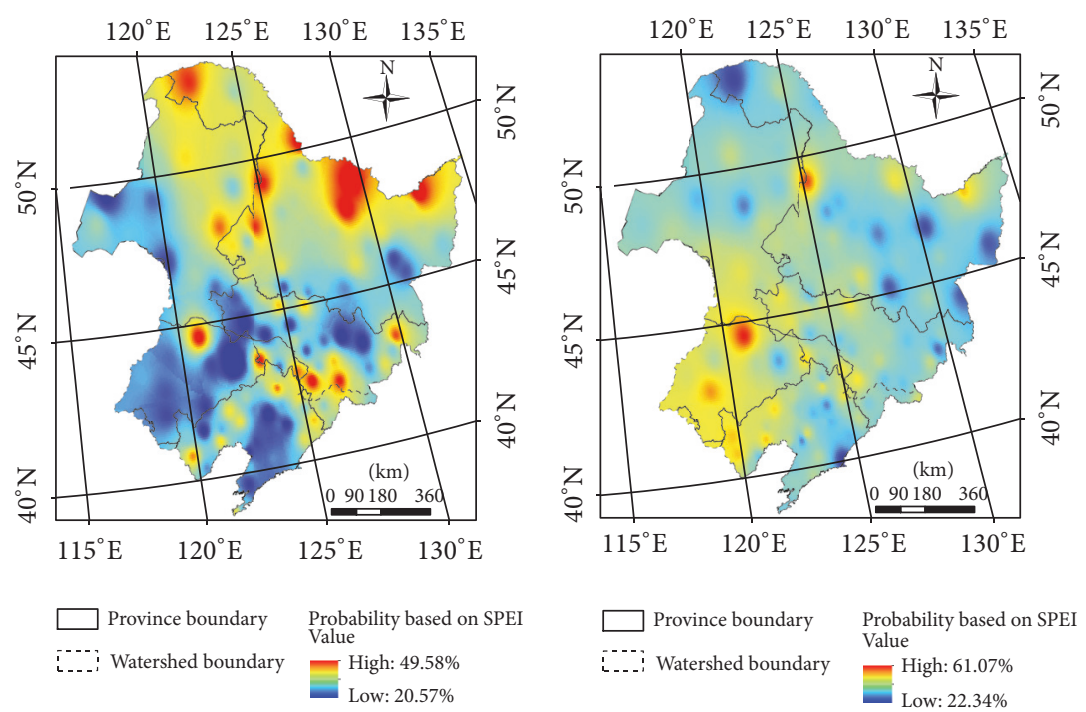

(b)
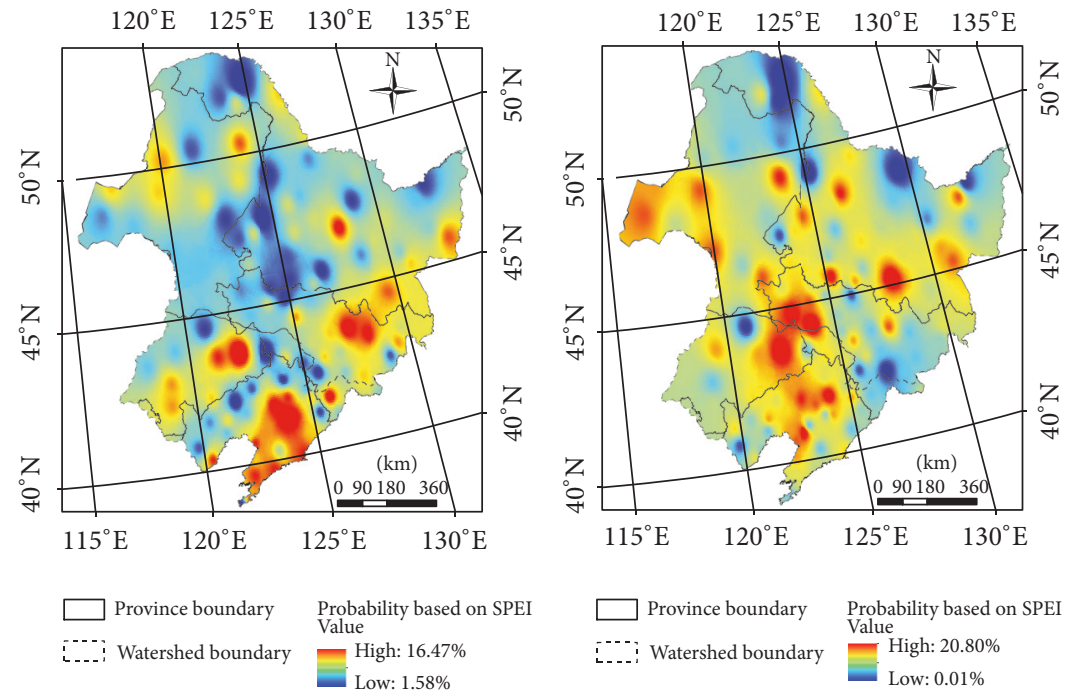

(c)

Figure 9: Continued. 

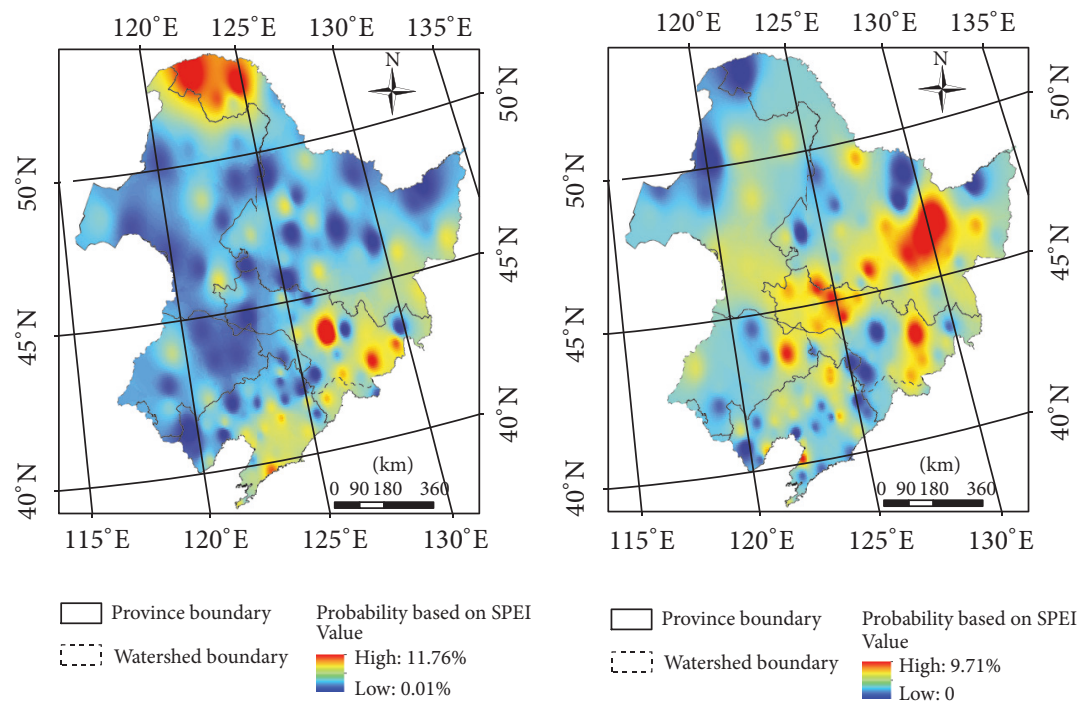

(d)
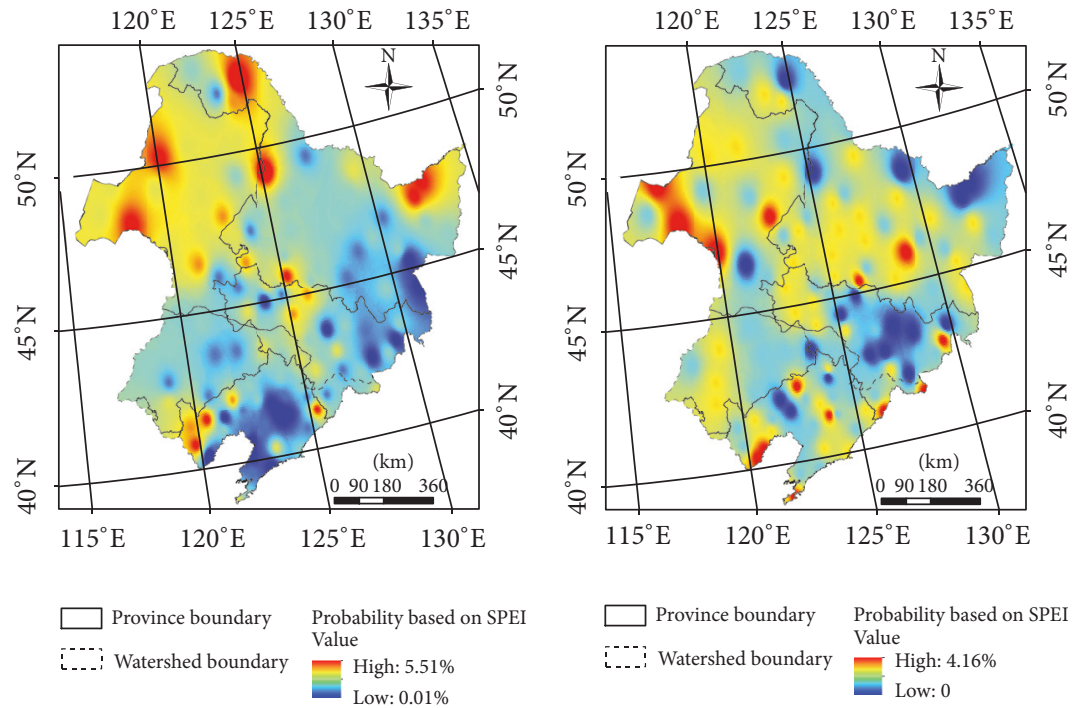

(e)

FIGURE 9: The comparison of spatial distribution of the happening probability of (a) drought, (b) light drought, (c) moderate drought, (d) severe drought, and (e) extreme drought between 1964 and 1994 (left) and between 1995 and 2013 (right).

probability of $49.58 \%$; moderate drought happened most probably in western SRB, eastern SRB, and most parts of LRB covered Liaoning province and southeastern Inner Mongolia with a highest occurrence rate of $16.74 \%$; severe drought occurred mostly in northwestern Heilongjiang province, eastern Jilin province, and parts of Inner Mongolia with a highest probability of $11.76 \%$; western SLRB, northeastern $\mathrm{SRB}$, and mid-SRB are the regions where the extreme drought most possibly happened with a highest ratio of $5.51 \%$.

Figure 9 (right) manifests that, after 1994, the drought most possibly happened in southeastern Inner Mongolia, western Liaoning province, and western Jilin province with a highest happening rate of $70.83 \%$; the light drought most possibly covered southern SRB and most regions of LRB with a highest probability of $61.07 \%$; moderate drought mostly occurred in eastern Inner Mongolia, southwestern Heilongjiang province, Liaoning province, and western Jilin province with a highest possibility of $20.80 \%$; eastern Inner Mongolia, eastern Heilongjiang province, western Jilin province, and northwestern Liaoning province are the places where severe drought most frequently happened at a highest ratio of $9.71 \%$; the extreme drought occurrence center moved to the mid-SRB and eastern SRB with a highest happening ratio of $4.16 \%$.

To further research the movement of intensive drought occurrence center, the difference of drought (with SPEI $\leq$ -0.5) happening probability before and after the climate abrupt change (1995-2013 minus 1964-1994) was calculated. From Figure 10, it can be seen that the decreased drought happening rate happened in the northern SLRB and small 


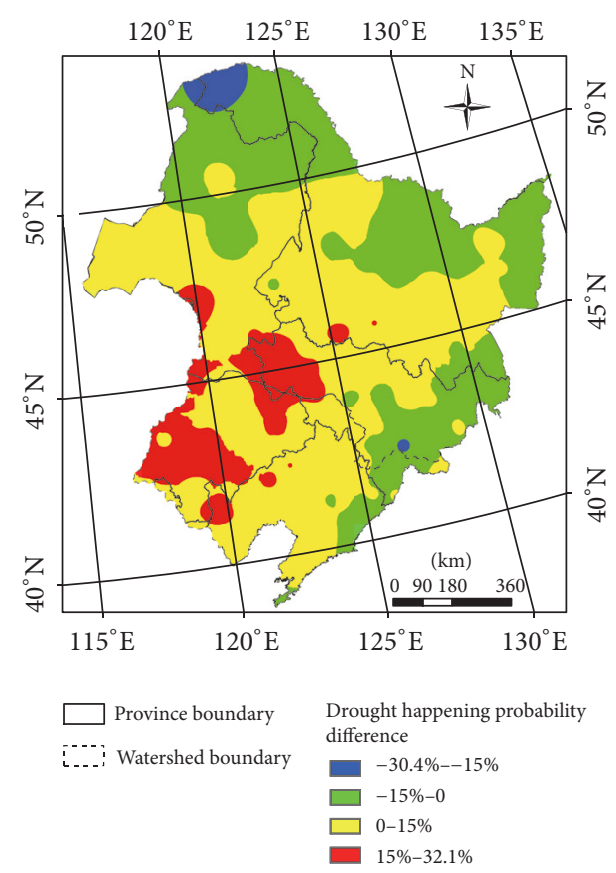

FIGURE 10: Spatial distribution of drought happening probability difference between 1964-1994 and 1995-2013 (1995-2013 minus 1964-1994) over the SLRB.

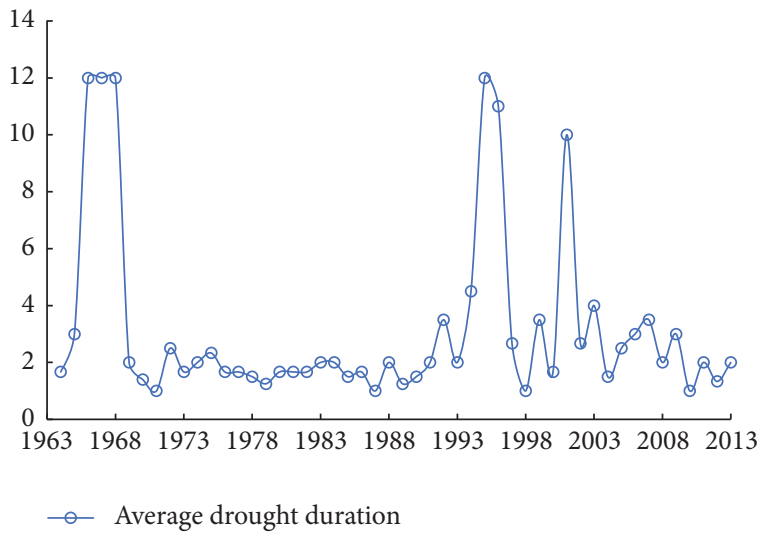

FIgURE 11: The interannual variability of average drought duration (number of months) from 1964 to 2013.

part of southeastern SLRB; meanwhile, the increased drought happening probability happened in southwestern SLRB. It demonstrates that the intensive drought occurrence regions altered from the northern SLRB to the southwestern SLRB.

4.7. Variations of Drought Duration. Figure 11 shows the variability of average drought (with SPEI $\leq-0.5$ ) duration from 1964 to 2013. The picture shows that the duration has a fluctuant declining trend before the 1990s, while it increases from the early 1990s with a sharp rising since 1994 and peaks at 12 month in 1995. The spatial distribution of drought (with SPEI $\leq-0.5$ ) duration difference between 1964-1994 and 1995-2013 over the SLRB is shown in Figure 12. It can be found that increased drought durations occurred in most parts of

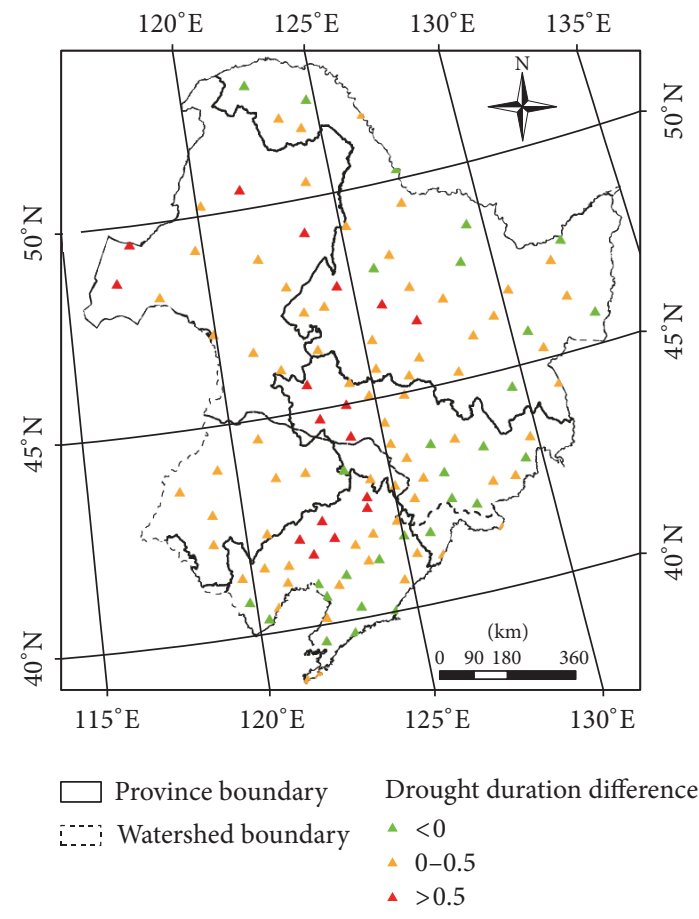

FIGURE 12: Spatial distribution of drought duration difference (number of months) between 1964-1994 and 1995-2013 (1995-2013 minus 1964-1994) over the SLRB.

SLRB; after the climate abrupt change, drought durations in most part of the basin have increased by less than half a month; even in parts of northwest Liaoning province, parts of west Jilin province, few part of Heilongjiang province, and few part of Inner Mongolia, the drought durations have increased by more than half a month; and only few parts of east SLRB have decreased drought durations.

\section{Conclusion}

This paper investigated the spatiotemporal drought variation patterns in SLRB. The important conclusions can be drawn as follows:

(1) Drought in SLRB is becoming serious and frequent for the last 50 years; a significant upward trend of annual drought occurred in SLRB since 1994; in seasonal scale, most of the drought events happened after 1994, especially in spring and summer.

(2) The drought percentage area and all degrees of drought influencing area in SLRB significantly expanded during 1964-2013, especially the light drought and the moderate drought affecting area. Moreover, drought affected area expanded in four seasons except winter during the last 50 years.

(3) There is a climate abrupt change which happened in around 1994; the SPEI values of most parts of SLRB including eastern Inner Mongolia, Liaoning province, western Jilin province, and southern and eastern Heilongjiang province have downward trends 
until the late 2000s; the area with declining SPEI is larger than that with declining SPI, which could be due to the rising temperature after the climate abrupt change.

(4) The happening probability of all degrees of drought increased to a comparatively high level after the abrupt change; at the same time, the intensive drought occurrence regions altered from the northern SLRB to the southwestern SLRB.

(5) The drought duration increases from the early $1990 \mathrm{~s}$ with a sharp rising since 1994; increased drought months occurred in most parts of SLRB, and the drought durations in most parts of the basin have increased by less than half a month after the climate abrupt change; only few parts of southeast and northeast SLRB have declined drought months.

(6) The expanding drought area, the increasing drought happening rate, the moving intensive drought occurrence center, and the long lasting drought duration have been and would continue leading to a severer negative impact on the development of social economy and agricultural production in northeastern China.

\section{Conflicts of Interest}

The authors declare that there are no conflicts of interest regarding the publication of this paper.

\section{Acknowledgments}

The work described in this paper was financially supported by the National Major Science and Technology Program for Water Pollution Control and Treatment (no. 2012ZX07201006), the Special Funds for Public Welfare Research Project in the Ministry of Water Resource (no. 201501013), and the National Natural Science Foundation of China (no. 51609261 and no. 51509266).

\section{References}

[1] Z. G. Ma and C. B. Fu, "Trend analysis of surface wetting condition in arid area in northern China," Journal of meteorological, vol. 59, no. 6, pp. 737-746, 2001.

[2] X. Zou, P. Zhai, and Q. Zhang, "Variations in droughts over China: 1951-2003," Geophysical Research Letters, vol. 32, no. 4, 2005.

[3] Y. B. Yao, A. X. Dong, Y. R. Wang, X. Y. Zhang, and J. H. Yang, "Comparative study on spring regional drought characteristics in China based on palmer drought index," Arid land geography, vol. 30, no. 1, pp. 22-27, 2007.

[4] B. He, A. Lü, J. Wu, L. Zhao, and M. Liu, "Drought hazard assessment and spatial characteristics analysis in China," Journal of Geographical Sciences, vol. 21, no. 2, pp. 235-249, 2011.

[5] M. X. Yu, Q. F. Li, M. J. Hayes, M. D. Svoboda, and R. R. Heim, "Are droughts becoming more frequent or severe in China based on the standardized precipitation evapotranspiration index: 1951-2010?" International Journal of Climatology, vol. 34, no. 3, pp. 545-558, 2014.
[6] K. Xu, D. Yang, H. Yang, Z. Li, Y. Qin, and Y. Shen, "Spatiotemporal variation of drought in China during 1961-2012: a climatic perspective," Journal of Hydrology, vol. 526, pp. 253264, 2015.

[7] X. Y. Song, L. J. Li, G. B. Fu et al., "Spatial-temporal variations of spring drought based on spring-composite index values for the Songnen Plain, Northeast China," Theoretical and Applied Climatology, vol. 116, no. 3-4, pp. 371-384, 2014.

[8] W. Palmer, "Meteorological droughts", in U.S. Department of Commerce, Weather Bureau Research Paper, pp. 45-58, 1965.

[9] T. B. McKee, N. J. Doesken, and J. Kleist, "The relationship of drought frequency and duration t time scales," in Proceedings of the Eighth Conference on Applied Climatology, American Meteorological Society, Anaheim, Calif, USA, 1993.

[10] S. M. Vicente-Serrano, S. Beguería, and J. I. López-Moreno, "A multiscalar drought index sensitive to global warming: the standardized precipitation evapotranspiration index," Journal of Climate, vol. 23, no. 7, pp. 1696-1718, 2010.

[11] W. Duan, F. Fan, and J. K. Yang, "Calculation and evaluation of area precipitation for river basin," Frontier of Environmental Science, vol. 3, no. 4, pp. 136-141, 2014.

[12] H. B. Mann, "Nonparametric tests against trend," Econometrica, vol. 13, pp. 245-259, 1945.

[13] M. G. Kendall, Rank Correlation Methods, Griffin, London, UK, 1975.

[14] J. H. Lee and C. J. Kim, "A multi model assessment of the climate change effect on the drought severity-duration-frequency relationship," Hydrological Processes, vol. 27, no. 19, pp. 2800-2813, 2013.

[15] M. Yang, D. Yan, Y. Yu, and Z. Yang, "SPEI-based spatiotemporal analysis of drought in Haihe River basin from 1961 to 2010," Advances in Meteorology, vol. 2016, Article ID 7658015, 10 pages, 2016.

[16] C. W. Thornthwaite, "An approach toward a rational classification of climate," Geographical Review, vol. 38, pp. 55-94, 1948.

[17] K. H. Hamed, "Trend detection in hydrologic data: the MannKendall trend test under the scaling hypothesis," Journal of Hydrology, vol. 349, no. 3-4, pp. 350-363, 2008.

[18] Z. J. Li, X. B. Li, and Z. M. Xu, "Impacts of water conservancy and soil conservation measures on annual runoff in the Chaohe River Basin during 1961-2005," Journal of Geographical Sciences, vol. 20, no. 6, pp. 947-960, 2010. 

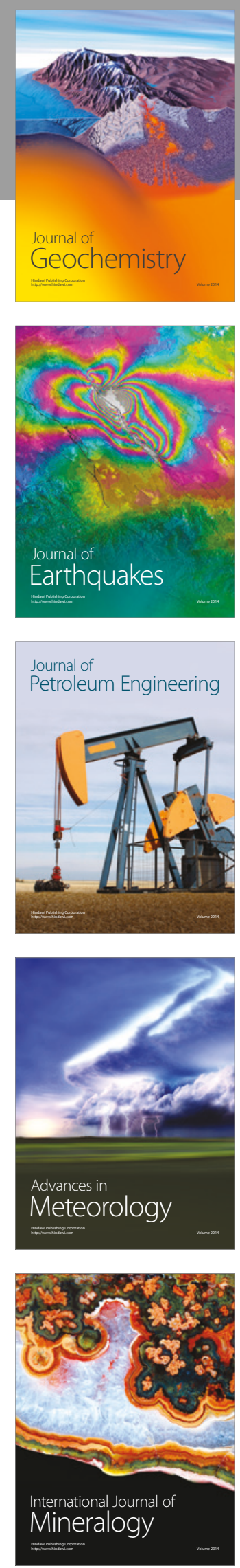
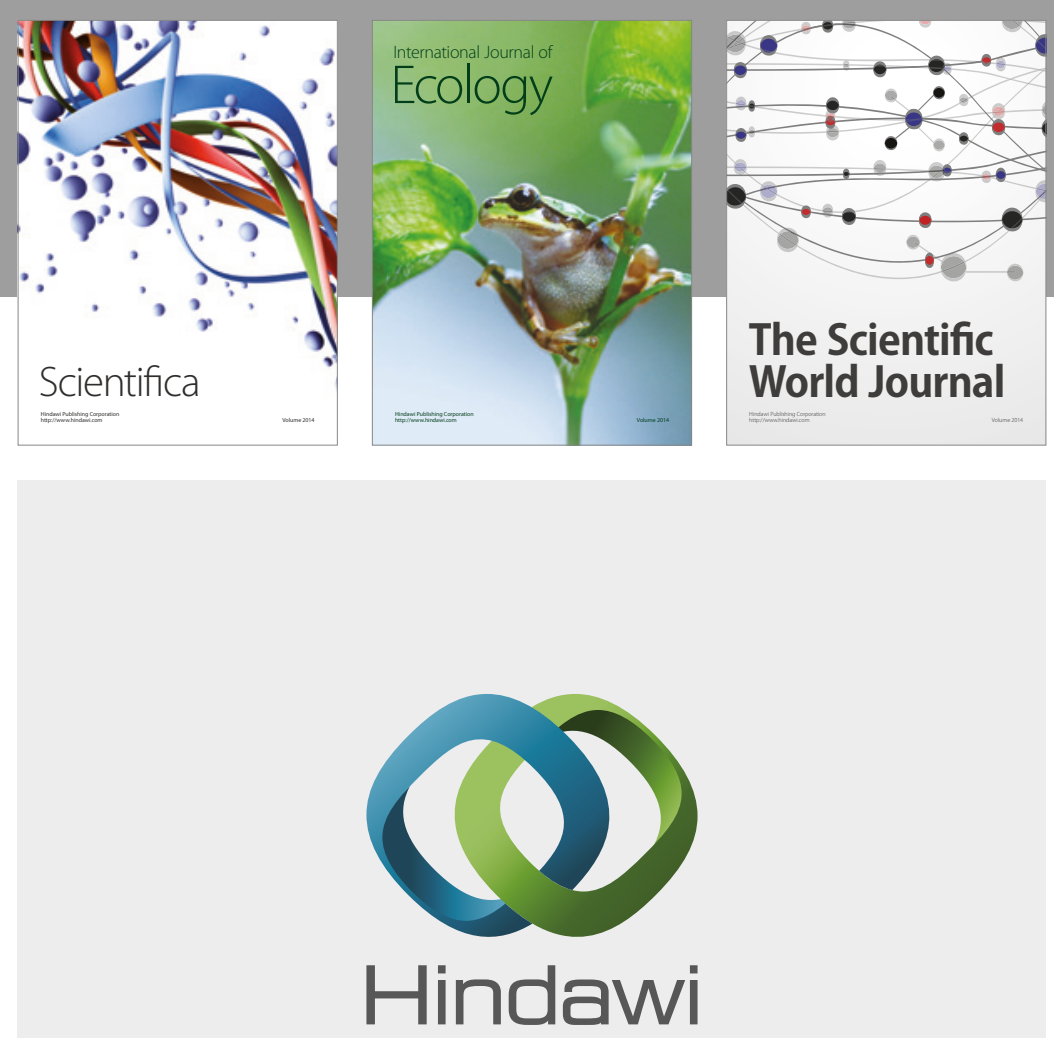

Submit your manuscripts at

https://www.hindawi.com
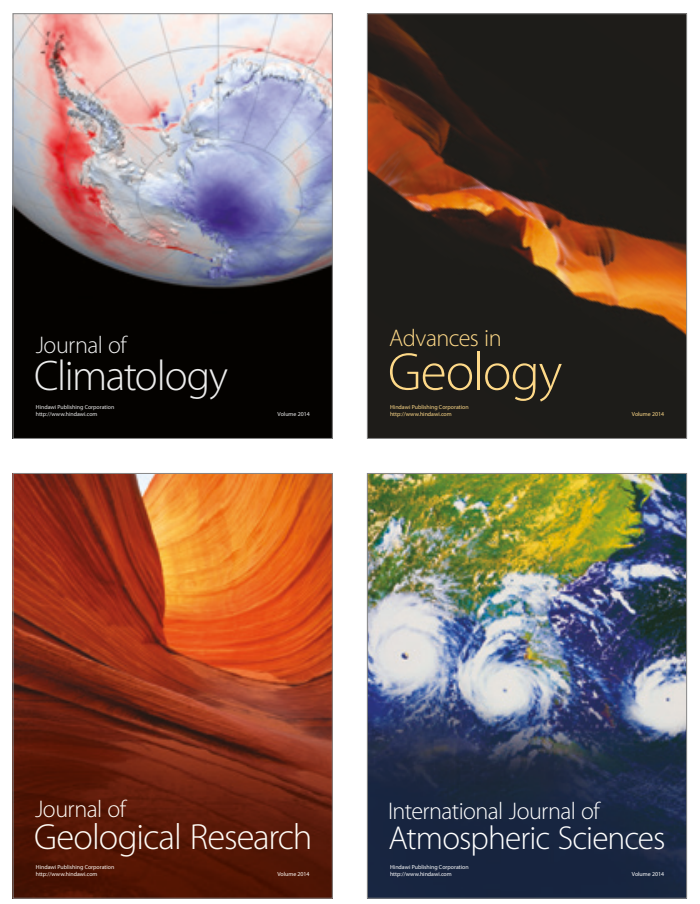

The Scientific

World Journal
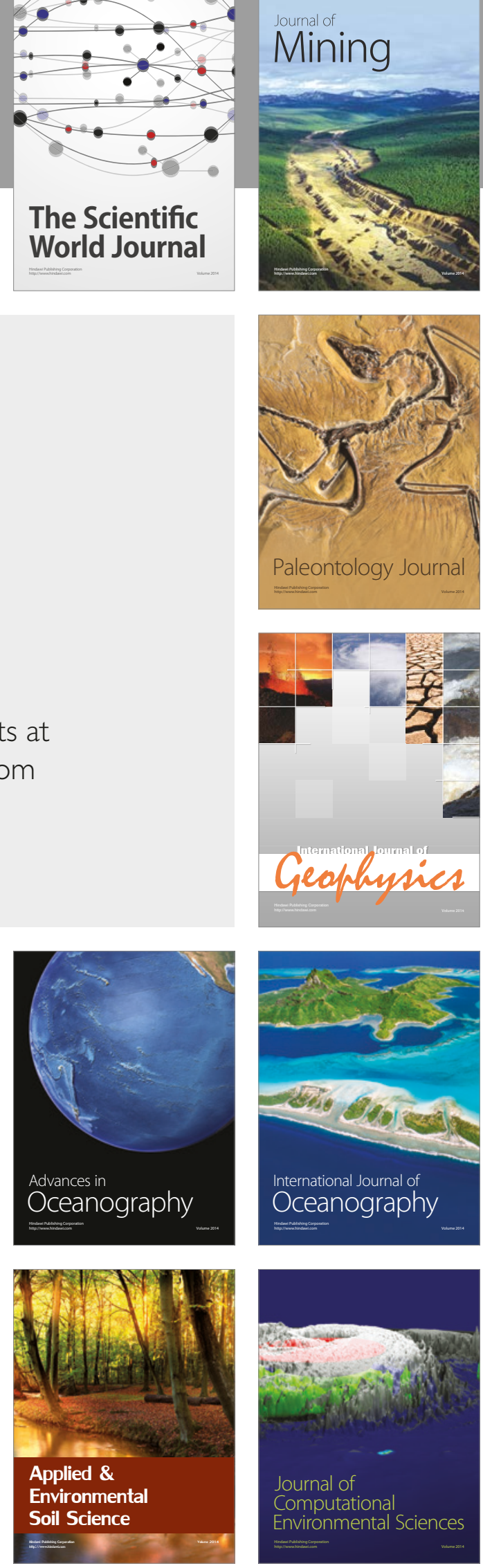